\title{
Single Incision Gasless Laparoscopic Surgeries and other Low-cost Minimally Invasive Techniques for Evaluation of Infertility in Rural Areas
}

\author{
${ }^{1}$ Linda Sailo, ${ }^{2}$ Gnanaraj Jesudian
}

\begin{abstract}
Single incision Lift laparoscopic surgeries offer a very attractive and low cost option of evaluation of infertility in rural areas. We describe this and other minimally invasive low cost methods used in evaluation and management of infertility in rural areas.

Keywords: Infertility, Laparoscopic surgeries, Single incision laparoscopic surgery, Minimally invasive surgeries.

How to cite this article: Sailo L, Jesudian G. Single Incision Gasless Laparoscopic Surgeries and other Low-Cost Minimally Invasive Techniques for Evaluation of Infertility in Rural Areas. Int J Infertil Fetal Med 2014;5(1):30-31.
\end{abstract}

Source of support: Nil

Conflict of interest: None

Date of Received: 03-12-13

Date of Acceptance: 01-04-14

Date of Publication: April 2014

\section{INTRODUCTION}

Infertility is a common condition affecting about out of 7 couples worldwide. ${ }^{1}$ It was difficult to evaluate infertility in women before diagnostic laparoscopy became available. Tests like hysterosalpingography were not accurate and it was difficult to diagnose conditions like adhesions, endometriosis, pelvic inflammatory, disease and so on with certainty. Now laparoscopic chromotubation is the gold standard of tubal evaluation. ${ }^{2}$ We describe the low cost minimally invasive procedures that we used for evaluation and treatment for infertility in a remote rural area in India

Diagnostic laparoscopy was carried out with gasless or lift laparoscopic single incision technique using the apparatus designed by Dr Daniel Kruschinski ${ }^{3}$ with the patient in lithotomy position and methylene blue chromotubation.

\footnotetext{
${ }^{1}$ Consultant, ${ }^{2}$ Director

${ }^{1}$ Department of Obstetrics and Gynecology, Bethesda Hospital and Research Center, Aizawl, Mizoram, India

${ }^{2}$ Department of Medical Services, Samiti for Education Environment, Health and Social Action, Coimbatore, Tamil Nadu, India

Corresponding Author: Gnanaraj Jesudian, Director, Department of Medical Services, Samiti for Education, Environment Health and Social Action, Karunya Community Hospital, Karunyanagar, Coimbatore, Tamil Nadu India, Phone: +919500127271 e-mail: jgnanaraj@gmail.com
}

Ovarian drilling was carried out for polycystic ovarian disease and when there tubes were blocked and dilated just tubal drilling was carried out at the most distal end of the tube near the ovary.

If there was a block, ureterorenoscope was used to visualize the fallopian tubal orifice. Normal saline was injected with great force using the pathfinder of the ureterorenoscope. Often this was sufficient to relieve the obstruction of blocked tubes (4 out of 16 in 2011). If this does not work, the next step is to dilate with 0.025 inch hydrophilic guide wire.

Submucous fibroids and Asherman's adhesions or synechiae were resected with resectoscope used for urology surgeries after dilating the cervix.

Table 1 shows the summary of the results of the procedures carried out at the Burrows Memorial Christian Hospital, SEESHA Karunya community hospital and Bethesda Hospital and Research center. The cosmetically attractive single incision lift laparoscopic surgeries (SILLS) were carried out in 2012. Figure 1 shows that a combination of open and laparoscopic surgical instruments could be used.

The instruments used for SILLS are sturdy, less expensive, easier to maintain, and hand instruments are similar to traditional open surgical instruments. However, the use of familiar open surgical instruments (see Fig. 1), lack of

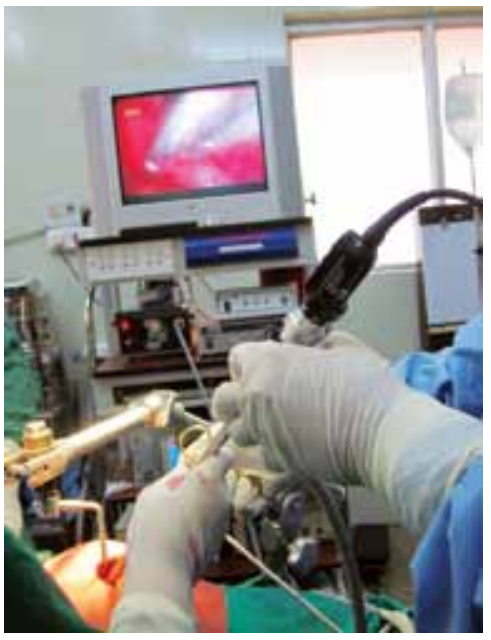

Fig. 1: A combination of laparoscopic and open instruments could be used with SILLS 
Table 1: Summary of results of low-cost minimally invasive surgery for infertility

\begin{tabular}{llll}
\hline Method & Period of study & No. of patients & Successful outcome \\
\hline Hydro-insufflation with normal saline using the & $2002-2009$ & 89 & 14 \\
Ureterorenoscope & $2011-2012$ & 16 & 4 \\
Adhesionolysis & $2002-2009$ & 152 & 2 \\
Endoscopic resection of fibroid/synechiae & $2002-2009$ & 18 & 0 \\
Tubal recanalization-laparoscopic & $2002-2009$ & 7 & 1 \\
Tubal recanalization-laparoscopy assisted & $2002-2009$ & 17 & 4 \\
Fallopian tubal drilling & $2011-2012$ & 19 & 12 \\
Ovarian drilling & $2011-2012$ & 59 & \\
Number of single incision gasless laparoscopies & $2011-2012$ & 83 & \\
carried out & & & \\
- Adhesiolysis & & & \\
- Ovarian drilling & & & \\
- Tubal drilling & & & \\
- Endometriosis resection & & \\
- Tubal patency testing & & \\
\hline
\end{tabular}

cross-over of instruments, and that the instruments could be passed one at a time make it easier to learn. For rural areas the advantages of short stay, less pain, faster recovery, and ability to perform under regional anesthesia and less expense and an easier learning makes it an ideal procedure for taking modern surgery to the poor and the marginalized.

\section{REFERENCES}

1. Available at: http://en.wikipedia.org/wiki/Infertility accessed on April 12, 2013.

2. Kodaman PH, Arici A, Seli E. Evidence-based diagnosis and management of tubal factor infertility. Curr Opin Obstet Gynecol 2004 Jun;16(3):221-229.

3. Available at: http://lift-laparoscopy.com/[accessed on April 5, 2013]. 